\title{
Thrombomodulin protects against lung damage created by high level of oxygen with large tidal volume mechanical ventilation in rats
}

\author{
Yoshiaki Iwashita ${ }^{1,3 \dagger}$, Erquan Zhang ${ }^{1 \dagger}$, Junko Maruyama ${ }^{1,4}$, Ayumu Yokochi ${ }^{1}$, Yasuharu Yamada ${ }^{1,4}$, Hirofumi Sawada ${ }^{1,2}$,
} Yoshihide Mitani ${ }^{2}$, Hiroshi Imai ${ }^{3}$, Koji Suzuki ${ }^{5}$ and Kazuo Maruyama ${ }^{1 *}$

\begin{abstract}
Background: Ventilator-induced lung injury (VILI) is associated with inflammatory responses in the lung. Thrombomodulin (TM), a component of the coagulation system, has anticoagulant and anti-inflammatory effects. We hypothesized that the administration of recombinant human soluble TM (rhsTM) would block the development of lung injury.

Methods: Lung injury was induced by high tidal volume ventilation for $2 \mathrm{~h}$ with 100\% oxygen in rats. Rats were ventilated with a tidal volume of $35 \mathrm{ml} / \mathrm{kg}$ with pretreatment via a subcutaneous injection of $3 \mathrm{mg} / \mathrm{kg} \mathrm{rhsTM}$ (HV (high tidal volume)/TM) or saline (HV/SAL) $12 \mathrm{~h}$ before mechanical ventilation. Rats ventilated with a tidal volume of $6 \mathrm{ml} / \mathrm{kg}$ under 100\% oxygen with rhsTM (LV (low tidal volume)/TM) or saline (LV/SAL) were used as controls. Lung protein permeability was determined by Evans blue dye (EBD) extravasation.

Results: Lung injury was successfully induced in the HV/SAL group compared with the LV/SAL group, as shown by the significant decrease in arterial oxygen pressure $\left(\mathrm{PaO}_{2}\right)$, increased protein permeability, and increase in mean pulmonary artery pressure (mPAP) and ratio of mean pulmonary artery pressure to mean artery pressure (Pp/Ps). Treatment of rats with lung injury with rhsTM (HV/TM) significantly attenuated the decrease in $\mathrm{PaO}_{2}$ and the increase in both mPAP and Pp/Ps, which was associated with a decrease in the lung protein permeability. Lung tissue mRNA expressions of interleukin (IL)-1 $a, I L-1 \beta, I L-6$, tumor necrosis factor- $a$, and macrophage inflammatory protein (MIP)-2 were significantly higher in HV than in LV rats. Rats with VILI treated with rhsTM (HV/TM) had significantly lower mRNA expressions of IL-1a, IL-1ß, IL-6, and MIP-2 than those expressions in HV/SAL rats.
\end{abstract}

Conclusions: Administration of rhsTM may prevent the development of lung injury created by high level of oxygen with large tidal volume mechanical ventilation, which has concomitant decrease in proinflammatory cytokine and chemokine expression in the lung.

Keywords: Ventilator-induced lung injury, Thrombomodulin, Pulmonary hypertension, Nitric oxide

\section{Background}

Mechanical ventilation can initiate or exacerbate lung injury, causing what is referred to as ventilator-induced lung injury (VILI) [1]. A high transalveolar pressure, tidal volume, and respiratory rate contribute to the development of VILI [2]. Mechanical force not only causes disruption of

\footnotetext{
* Correspondence: k-maru@clin.medic.mie-u.ac.jp

${ }^{\dagger}$ Equal contributors

'Department of Anesthesiology and Critical Care Medicine, School of Medicine, Mie University, 2-174 Edobashi, Tsu, Mie 5148507, Japan Full list of author information is available at the end of the article
}

the lung tissue but also induces biochemical changes in the lung, leading to an upregulation of inflammatory responses, such as increased neutrophil infiltration and inflammatory mediators in bronchoalveolar lavage fluid and the lung tissue $[3,4]$. Minimizing alveolar overdistension with a low tidal volume attenuates inflammatory changes in VILI [5] and improves the mortality of acute respiratory distress syndrome (ARDS) patients [6] and abdominal surgical patients under general anesthesia [7]. In an animal model of VILI, mechanical ventilation caused a procoagulant and anti-fibrinolytic state, so-called ventilator- 
associated coagulopathy, as evidenced by an increase in thrombin-antithrombin complex and plasminogen activator inhibitor-1 $[8,9]$.

Thrombomodulin (TM) is a transmembrane glycoprotein receptor for thrombin that has anticoagulant and antiinflammatory effects [10-12]. Thrombin converts fibrinogen to fibrin. Binding of fibrin to monocytes activates nuclear factor kappa B (NF-kB), which activates proinflammatory cytokine production $[9,13]$. Thrombin also activates protease-activated receptors (PARs) on the cell surface and subsequently stimulates the production of adhesion molecules in endothelium and leukocytes [14] and interleukin (IL)-6 and IL-8 in endothelial cells [15], thereby potentiating leukocyte chemotaxis and adhesion. These effects of thrombin are associated with VILI, with an earlier study showing an increase in intracellular adhesion molecules in macrophages obtained by the lung lavage from rats with VILI [3].

Binding of TM to thrombin to assemble the thrombinTM complex has the following effects: (1) activation of protein $\mathrm{C}$ to form activated-protein $\mathrm{C}$ (APC) which inhibits factors $\mathrm{Va}$ and VIIIa and suppresses further thrombin formation; (2) sequestration of thrombin, thereby reducing fibrin formation; (3) formation of thrombin-activatable fibrinolysis inhibitor and subsequent C5a inactivation; and (4) inhibition of high-mobility group box 1 (HMGB$1)$, a late mediator of sepsis $[11,16]$. These effects of TM antagonize thrombin's procoagulant and proinflammatory activity, which are exerted via the TM expressed on vascular endothelial cells [10-12].

Recently, recombinant human soluble TM (rhsTM) was approved for the treatment of disseminated intravascular coagulopathy (DIC) in Japan [12]. Patients with sepsis associated with DIC tend to receive mechanical ventilation under oxygen inhalation at high concentrations. Because we hypothesized that administration of an exogenous TM such as rhsTM would prevent the development of lung injury, the purpose of this study was to determine if rhsTM administration ameliorates lung injury created by high level of oxygen with large-tidal volume mechanical ventilation in rats

\section{Methods}

\section{Animals}

Male Sprague-Dawley rats (Clea, Japan) weighing 250-350 $\mathrm{g}$ were used. The animal experiments committee of the Mie University School of Medicine, Mie, Japan approved the study protocol.

\section{Preliminary experiment}

In a preliminary experiment performed to select the experimental condition for induction of VILI in rats, 29 rats were assigned to one of the seven groups and ventilated under the following tidal volume conditions: (1) $6 \mathrm{ml} / \mathrm{kg}$ under room air (low tidal volume (LV) 6),
(2) $20 \mathrm{ml} / \mathrm{kg}$ under room air (HV20), (3) $30 \mathrm{ml} / \mathrm{kg}$ under room air (HV30), (4) $35 \mathrm{ml} / \mathrm{kg}$ under room air (HV35), (5) $40 \mathrm{ml} / \mathrm{kg}$ under room air (HV40), (6) 35

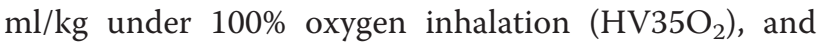
(7) $40 \mathrm{ml} / \mathrm{kg}$ under $100 \%$ oxygen inhalation $\left(\mathrm{HV}_{40 \mathrm{O}_{2}}\right)$. After mechanical ventilation for $2 \mathrm{~h}$ with the assigned tidal volume, Evans blue dye (EBD) extravasation was measured as an index of lung protein permeability. EBD strongly binds to albumin and is used as a marker of protein extravasation in lung injury models $[9,17,18]$. Based on these results (Figure 1), we decided to induce lung injury via a tidal volume of $35 \mathrm{ml} / \mathrm{kg}$ under $100 \%$ oxygen inhalation.

\section{Mechanical ventilation}

A tracheostomy was performed under intraperitoneal pentobarbital $(45 \mathrm{mg} / \mathrm{kg})$ anesthesia and a plastic cannula (SP-110; Natsume, Tokyo, Japan) was inserted into the trachea. The rats were then ventilated using an SN-480-7 volume cycle ventilator (Shinano Co., Nagoya City, Japan). Muscle relaxation was achieved using pancuronium bromide $(0.1 \mathrm{mg} / \mathrm{kg})$. Positive end-expiratory pressure was not applied. To maintain arterial carbon dioxide tension at a pressure between $40-50 \mathrm{mmHg}$, the respiratory rate was adjusted to be $30-100$ breaths/min, and the dead space was adjusted by inserting a tube between the Y-piece of the ventilator circuit and tracheostomy cannula in the high tidal volume group.

\section{Experimental group}

Twenty rats were divided into four groups as follows: (1) rats pretreated with saline and ventilated with a tidal volume of $6 \mathrm{ml} / \mathrm{kg}$ under 100\% oxygen inhalation (LV/ saline $(\mathrm{SAL}))(n=5)$; (2) rats pretreated with rhsTM and ventilated with a tidal volume of $6 \mathrm{ml} / \mathrm{kg}$ under $100 \%$ oxygen inhalation (LV/TM) $(n=5)$; (3) rats pretreated with saline and ventilated with a tidal volume of $35 \mathrm{ml} /$ $\mathrm{kg}$ under $100 \%$ oxygen inhalation (HV/SAL) $(n=5)$; and (4) rats pretreated with rhsTM and ventilated with a tidal volume of $35 \mathrm{ml} / \mathrm{kg}$ under $100 \%$ oxygen inhalation $(\mathrm{HV} / \mathrm{TM})(n=5)$. The rats were subcutaneously injected with $3 \mathrm{mg} / \mathrm{kg}$ of rhsTM (Asahi Kasei Pharma, Tokyo, Japan) dissolved in saline or saline alone $12 \mathrm{~h}$ before the start of the mechanical ventilation. In a previous study, we showed that plasma rhsTM levels were elevated after $9 \mathrm{~h}$ and remained elevated for $48 \mathrm{~h}$ after subcutaneous rhsTM injection [19].

\section{Catheterization}

The left internal carotid artery was cannulated for measuring artery pressure and sampling for arterial blood gas analysis. A pulmonary artery catheter (Silastic tubing, $0.31 \mathrm{~mm}$ inner diameter and $0.64 \mathrm{~mm}$ outer diameter) was inserted via the right external jugular vein into the 


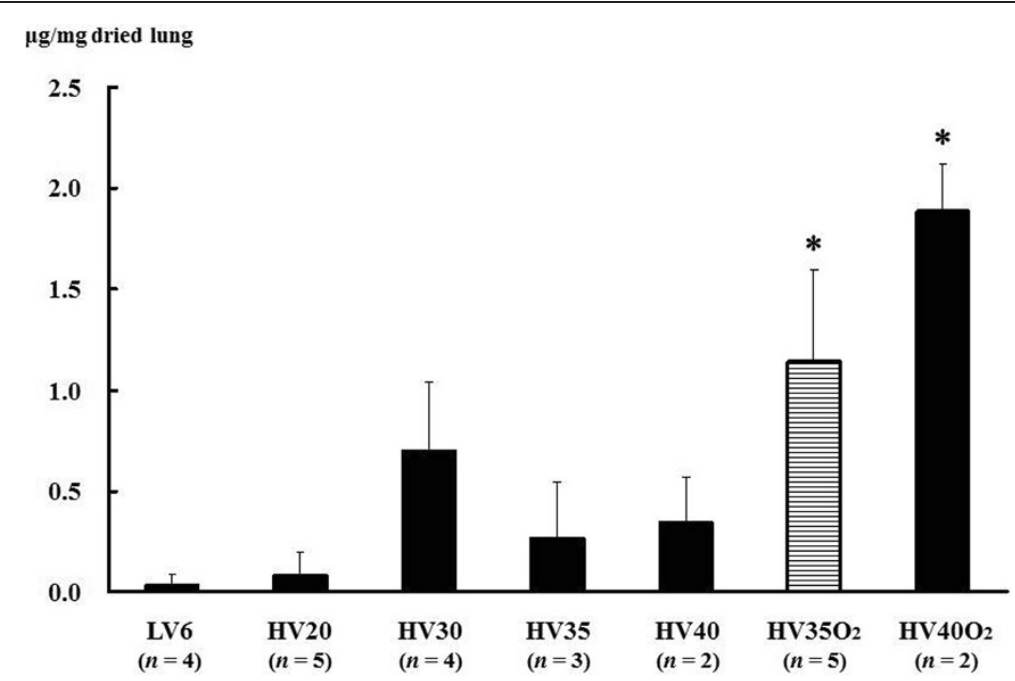

Figure 1 Preliminary experiment: Evans blue dye (EBD) extravasation as an estimate of lung protein permeability for different tidal volumes, with and without $100 \%$ oxygen inhalation. LV6, rats ventilated under room air with a tidal volume of $6 \mathrm{ml} / \mathrm{kg} ; \mathrm{HV} 2 \mathrm{O}, \mathrm{HV} 30, \mathrm{HV} 35$, $\mathrm{HV} 40$, rats ventilated under room air with tidal volumes of $20,30,35$, and $40 \mathrm{ml} / \mathrm{kg}$, respectively; $\mathrm{HV}_{3} \mathrm{O}_{2}$ and $\mathrm{HV} 40 \mathrm{O}_{2}$, rats ventilated with tidal volumes of 35 and $40 \mathrm{ml} / \mathrm{kg}$ under $100 \%$ oxygen inhalation, respectively. Bars indicate mean \pm SE. ${ }^{*} P<0.05$ versus the LV6 group. $n=$ number of rats treated with mechanical ventilation.

pulmonary artery using the closed-chest technique, as previously described $[19,20]$. Airway pressure was measured at the tracheostomy cannula. Mean artery pressure (mAP), mean pulmonary artery pressures (mPAP), and airway pressure were recorded with a physiological transducer and amplifier system (AP 620; Nihon Kohden, Tokyo, Japan). The ratio of mPAP to $\mathrm{mAP}(\mathrm{Pp} / \mathrm{Ps})$ was calculated as an estimate of pulmonary hypertension.

\section{Experimental protocol}

All rats were initially ventilated with a tidal volume of $6 \mathrm{ml} / \mathrm{kg}$. After a 15-min stabilization, an intravenous injection of $30 \mathrm{mg} / \mathrm{kg}$ EBD was given. Baseline arterial blood gas analysis was performed before the assignment of experimental tidal volume. After a 30-min stabilization, a tidal volume of 6 or $35 \mathrm{ml} / \mathrm{kg}$ was assigned, and mechanical ventilation was continued for another $2 \mathrm{~h}$. Further arterial blood samples were obtained every $30 \mathrm{~min}$ after the assignment of a tidal volume and were analyzed by a portable blood gas analyzer (iSTAT Analyzer 200; Abbott Point Care Inc., Princeton, NJ, USA). Alveolararterial oxygen difference $\left(\mathrm{A}-\mathrm{aDO}_{2}\right)$ was calculated with the following formula: $\mathrm{A}-\mathrm{aDO} \mathrm{OD}_{2}=(760-47) \times 1.0-\mathrm{PaCO}_{2} /$ $0.8-\mathrm{PaO} 2=713-\mathrm{PaCO}_{2} / 0.8-\mathrm{PaO} 2$. At the end of the protocol, the lung tissue was obtained to measure the lung water content and pulmonary microvascular permeability.

\section{EBD extravasation and the lung dry/wet weight ratio}

EBD extravasation into the lung as an estimate of protein permeability was quantitated as previously described $[17,18]$. After thoracotomy, the upper lobe of the right lung was ligated and harvested to determine the lung water content. The rest of the lung was perfused via the pulmonary artery for $2 \mathrm{~min}$ with saline to eliminate residual blood and EBD from the pulmonary bed [18]. After perfusion, the left lung was excised, rinsed externally with saline, and then placed in a drying oven at $90^{\circ} \mathrm{C}$ for $24 \mathrm{~h}$. Dried tissue samples were placed in $2 \mathrm{ml}$ formamide at $37^{\circ} \mathrm{C}$ for $24 \mathrm{~h}$. The EBD concentration was measured by dual wavelength spectrophotometry at 620 and $740 \mathrm{~nm}$, which allows for the correction of contaminating heme pigments. The corrected absorbance at $620 \mathrm{~nm}$ was calculated using the following formula: Corrected absorbance at $620 \mathrm{~mm}=$ actual absorbance at $620 \mathrm{~mm}-[1.426$ (absorbance at $740 \mathrm{~mm}$ ) - 0.03]. The total amount of EBD in the dried lung sample was calculated, and EBD extravasation was expressed as micrograms per gram of the dried lung tissue sample. The upper lobe of the right lung was placed in a drying oven at $90^{\circ} \mathrm{C}$ for $24 \mathrm{~h}$. The lung dry-to-wet weight (dry/wet) ratio as an estimate of lung water content was determined by the following formula: (wet lung weight - dried lung weight)/wet lung weight $\times 100(\%)$.

cDNA preparation and real-time polymerase chain reaction In another set of experiments with 21 rats [(LV/SAL) $(n=5), \mathrm{LV} / \mathrm{TM}(n=5), \mathrm{HV} / \mathrm{SAL}(n=6)$, and HV/TM $(n=5)]$, the lung samples were obtained for real-time polymerase chain reaction (PCR) and Western blotting. Interleukin (IL)-1 $\alpha$, IL-1 $\beta$, IL- 6 , tumor necrosis factor- $\alpha$ (TNF $\alpha$ ), macrophage inflammatory protein (MIP)-2, rhoassociated kinase (ROCK)-1, and HMGB-1 mRNA levels 
were determined by real-time PCR. After the extraction of total RNA from whole lung tissue [LV/SAL $(n=5)$, LV/TM $(n=5), \mathrm{HV} / \mathrm{SAL}(n=6), \mathrm{HV} / \mathrm{TM}(n=5)]$ using TRIzol reagent (Invitrogen, Carlsbad, CA, USA), cDNA synthesis was performed with ReverTra Ace (Toyobo Co., Ltd., Biochemical Operations Department, Osaka, Japan). Amplification was performed with a StepOne Plus Real Time PCR System (Applied Biosystems, Thermo Fisher Scientific, Waltham, MA, USA). The sequences of the primer pairs are listed in Table 1. Relative quantification was performed with the comparative $\Delta \Delta \mathrm{Ct}$ method by normalization with $\beta$-actin mRNA.

\section{Western blotting}

Western blotting for ROCK-1 and HMGB-1 in whole lung tissue was performed as described previously [19]. Three kinds of primary antibodies (anti-HMGB-1, 1:5,000, \#3935S, (Cell Signaling Technology, Danvers, MA, USA); anti-ROCK-1, 1:5,000 dilution, 611136, (BD Transduction Laboratories, San Jose, CA, USA); anti- $\beta$-actin, 1:200,000 dilution, A5441 (Sigma-Aldrich, St. Louis, MO, USA)) were incubated at $4{ }^{\circ} \mathrm{C}$ overnight. Secondary antibodies (anti-mouse IgG-HRP, 1:20,000 dilution, NA 931, Amersham; anti-rabbit IgG-HRP, 1:20,000 dilution, D2313, Santa Cruz Biotechnology, Dallas, TX, USA) were incubated for $1 \mathrm{~h}$ at room temperature.

\section{Data analysis}

Values are expressed as mean $\pm \mathrm{SE}$. When more than two means were compared, one-way analysis of variance was used. When significant variance was found, Fisher's predicted least significant difference test was used to

Table 1 Primer list

\begin{tabular}{|c|c|}
\hline Gene name & Primer $\left(5^{\prime}-3^{\prime}\right)$ sequence \\
\hline \multirow[t]{2}{*}{ IL-1a } & F: AAGACAAGCCTGTGTTGCTGAAGG \\
\hline & R: TCCCAGAAGAAAATGAGGTCGGTC \\
\hline \multirow[t]{2}{*}{$\mid L-1 \beta$} & F: CACCTCTCAAGCAGAGCACAG \\
\hline & R: GGGTTCCATGGTGAAGTCAAC \\
\hline \multirow[t]{2}{*}{ IL-6 } & F: TCCTACCCCAACTTCCAATGCTC \\
\hline & R: TTGGATGGTCTTGGTCCTTAGCC \\
\hline \multirow[t]{2}{*}{ MIP-2 } & F: CCAACCATCAGGGTACAGGG \\
\hline & R: GGGTCGTCAGGCATTGACA \\
\hline \multirow[t]{2}{*}{ HMGB-1 } & F: GGCTGACAAGGCTCGTTATG \\
\hline & R GGGCGGTACTCAGAACAGAA \\
\hline \multirow[t]{2}{*}{ TNFa } & F: AAATGGGCTCCCTCTCATCAGTTC \\
\hline & R: TCTGCTTGGTGGTTTGCTACGAC \\
\hline \multirow[t]{2}{*}{ ROCK-1 } & F: TCTCATTTGTGCCTTCCTTACG \\
\hline & R: GTTTCCCAAGCCCACTGATC \\
\hline \multirow[t]{2}{*}{ ACTB } & F: GACGGTCAGGTCATCACTATCG \\
\hline & R: TAG TTTCATGGATGCCACAGGAT \\
\hline
\end{tabular}

establish which groups were different. $P<0.05$ was considered to be significant.

\section{Results}

Preliminary experiment: effect of tidal volume and $100 \%$ oxygen inhalation

In a preliminary experiment, we evaluated the conditions required to induce experimental lung injury in rats. EBD extravasation increased with escalation in tidal volume but did not reach significant difference in room air, probably because of the relatively small number of samples. Under $100 \% \mathrm{O}_{2}$ inhalation, EBD extravasation was significantly increased in the $\mathrm{HV}_{3} 5 \mathrm{O}_{2}$ and $\mathrm{HV} 40 \mathrm{O}_{2}$ groups compared with the LV6 group (Figure 1). There was no significant difference between the LV6 group and the HV20, HV30, HV35, or HV40 groups. Overall, the results suggested that a high tidal volume with $100 \%$ oxygen tended to cause high EBD extravasation, an estimate of the lung protein permeability. We wanted to select the specific condition for obtaining a stable lung injury model in an experimental setting. Two out of four rats in the $\mathrm{HV} 40$ and $\mathrm{HV}_{40 \mathrm{O}_{2}}$ groups became unstable and died so we decided to induce lung injury in rats by ventilating with $35 \mathrm{ml} / \mathrm{kg}$ and 100\% oxygen in subsequent experiments in which the protective effects of TM for the development of VILI were determined. Several other studies also induced lung injury under $100 \%$ oxygen inhalation [2,21,22]. An earlier study showed that ventilation with $35 \mathrm{ml} / \mathrm{kg}$ tidal volume for $156 \mathrm{~min}$ compromise systemic circulation, leading to shock [23], in which ventilation time is longer than our study (2 h).

\section{Arterial oxygen pressure, $\mathrm{A}-\mathrm{aDO}_{2}, \mathrm{EBD}$ extravasation, and the lung dry/wet weight ratio}

$\mathrm{PaO}_{2}$ was significantly decreased in the HV/SAL group compared with the LV/SAL group at 1, 1.5, and $2 \mathrm{~h}$ after the start of mechanical ventilation. The decrease in $\mathrm{PaO}_{2}$ was significantly attenuated in the HV/TM group compared with the HV/SAL group at 1 and $2 \mathrm{~h}$. There was no difference in $\mathrm{PaO}_{2}$ between the $\mathrm{HV} / \mathrm{TM}$ and $\mathrm{LV}$ groups. Thus, the decrease in $\mathrm{PaO}_{2}$ with high tidal ventilation was prevented by TM treatment (Figure 2A). These results were confirmed with $\mathrm{A}-\mathrm{aDO}_{2}$, an estimate of oxygenation that excludes the effect of alveolar carbon dioxide. EBD extravasation, a marker of protein permeability, was significantly increased in the HV/SAL group and HV/TM group compared with the LV/SAL group and LV/TM group, respectively (Figure 2C). Although not significant, the lung dry/wet ratio tended to be increased in the HV/SAL group and HV/TM group compared with the LV/SAL group and LV/TM group, respectively (Figure 2D). The increase in EBD extravasation and the lung dry/wet weight ratio was lower in HV/TM rats than in $\mathrm{HV} / \mathrm{SAL}$ rats (Figure 2C, D) but did not reach 

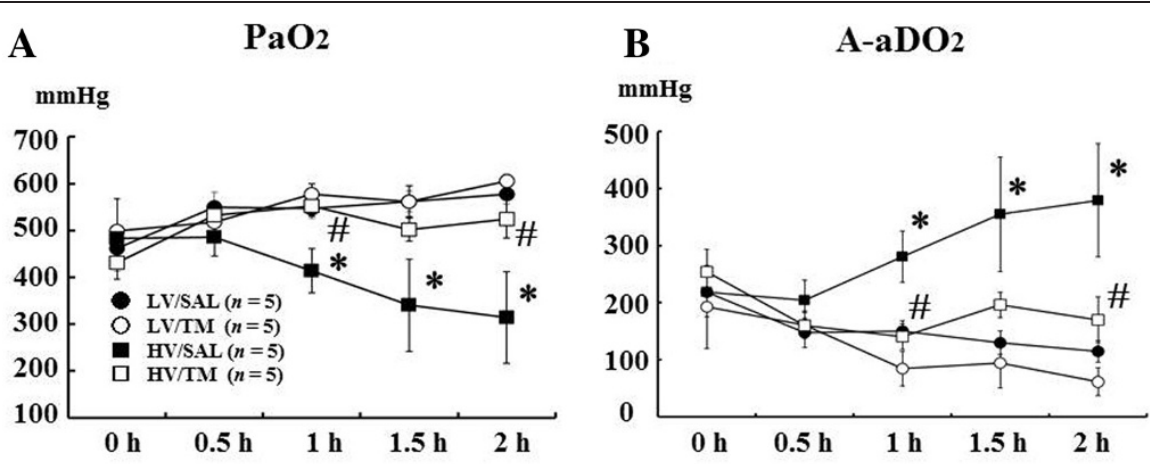

\section{EBD Extravasation}
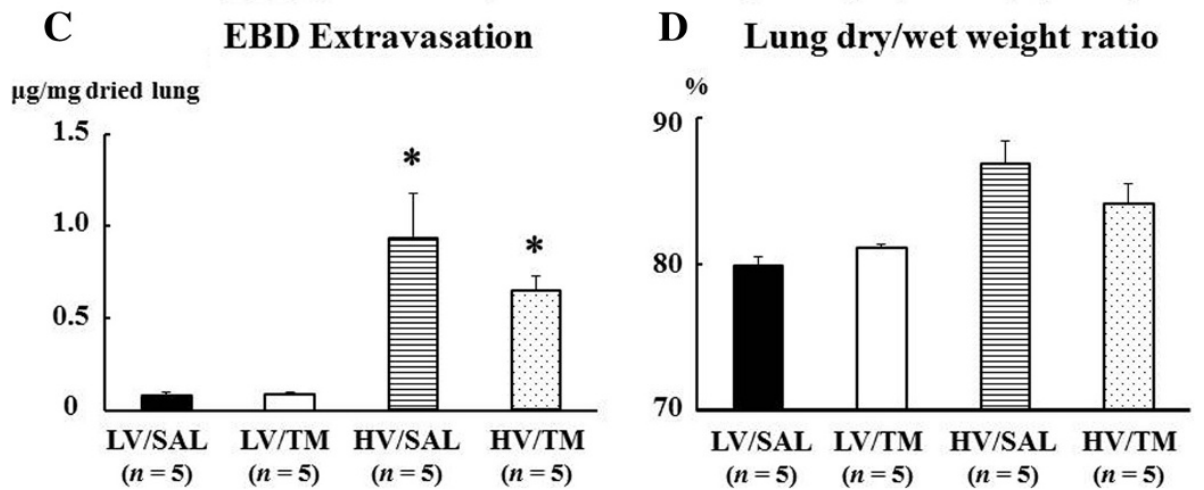

Figure 2 Arterial oxygen pressure, $\mathrm{A}-\mathrm{aDO}_{2}$, Evans blue dye (EBD) extravasation, and the lung dry/wet weight ratio. (A) Arterial oxygen pressure $\left(\mathrm{PaO}_{2}\right),(\mathbf{B})$ alveolar-arterial oxygen difference $\left(\mathrm{A}-\mathrm{aDO}_{2}\right),(\mathbf{C}) \mathrm{EBD}$ extravasation, an estimate of protein permeability, (D) the lung dry-to-wet (dry/wet) weight ratio, an estimate of the lung water content. LV low tidal volume $(6 \mathrm{ml} / \mathrm{kg}), H V$ high tidal volume (35 $\mathrm{ml} / \mathrm{kg}), S A L \mathrm{saline}$, TM thrombomodulin. $0 \mathrm{~h}$, baseline measurement (tidal volume of $6 \mathrm{ml} / \mathrm{kg}$ ) before the assignment of experimental tidal volume; $0.5,1,1.5$, and $2 \mathrm{~h}$, hours after the assignment of experimental tidal volume $(6 \mathrm{ml} / \mathrm{kg}$ or $35 \mathrm{ml} / \mathrm{kg})$. Bars indicate mean $\pm \mathrm{SE}$. ${ }^{*} P<0.05$ versus the respective LV groups. $\# P<0.05$ versus the HV/SAL group. $n=$ number of rats.

significance because of small number of experiment animals. Overall, these results showed that the HV/TM group had less lung injury, as measured by three independent methods, than the HV/SAL (positive control) group, suggesting that TM administration might ameliorate lung injury associated with high tidal volume ventilation.

\section{mPAP and Pp/Ps}

Because pulmonary artery pressure increases in severe lung injury [24], we measured mPAP. As we expected, mPAP was significantly higher in HV/SAL rats than in $\mathrm{LV} / \mathrm{SAL}$ rats at $1,1.5$, and $2 \mathrm{~h}$ after the start of mechanical ventilation. The increase in mPAP was significantly attenuated in the HV/TM group compared with the HV/SAL group at 1 and $1.5 \mathrm{~h}$. There were no differences in the mPAP between the HV/TM and LV groups (Figure 3A), suggesting that TM treatment prevented the increase in mPAP caused by high tidal volume ventilation. Similar results were obtained for $\mathrm{Pp} / \mathrm{Ps}$, an index of pulmonary hypertension [25]. $\mathrm{Pp} / \mathrm{Ps}$ was significantly higher in $\mathrm{HV} / \mathrm{SAL}$ rats than LV/SAL rats at 1.5 and $2 \mathrm{~h}$ after the start of mechanical ventilation. The increase in $\mathrm{Pp} / \mathrm{Ps}$ was significantly attenuated in the HV/TM group compared with the HV/SAL group at $1,1.5$, and $2 \mathrm{~h}$. There were no differences in the $\mathrm{Pp} / \mathrm{Ps}$ between the HV/TM group and $\mathrm{LV}$ groups (Figure $3 \mathrm{~B}$ ). The results of $\mathrm{mPAP}$ and $\mathrm{Pp} / \mathrm{Ps}$ are suggestive of the effects of TM-inhibiting pulmonary hypertension induced by hypercytokinemia due to the lung injury created by high level of oxygen with large-tidal volume mechanical ventilation.

\section{Peak inspiratory airway pressure}

Peak inspiratory airway pressure (PIP) was significantly increased in the HV/SAL group and HV/TM group compared with the LV/SAL group and LV/TM group, respectively. There was no difference between the $\mathrm{HV} /$ TM group and HV/SAL group (Figure 3C). PIP might be insensitive to detect the effect of TM on the lung injury created by high level of oxygen with large-tidal volume mechanical ventilation.

\section{Inflammatory cytokines and chemokines}

To confirm that the inflammatory response is accentuated in HV/SAL rats compared with LV/SAL rats, we measured cytokine and chemokine mRNA levels in the lungs. IL- $1 \alpha$, IL-1 $\beta$, IL-6, TNF $\alpha$, and MIP-2 mRNA levels in the lungs 


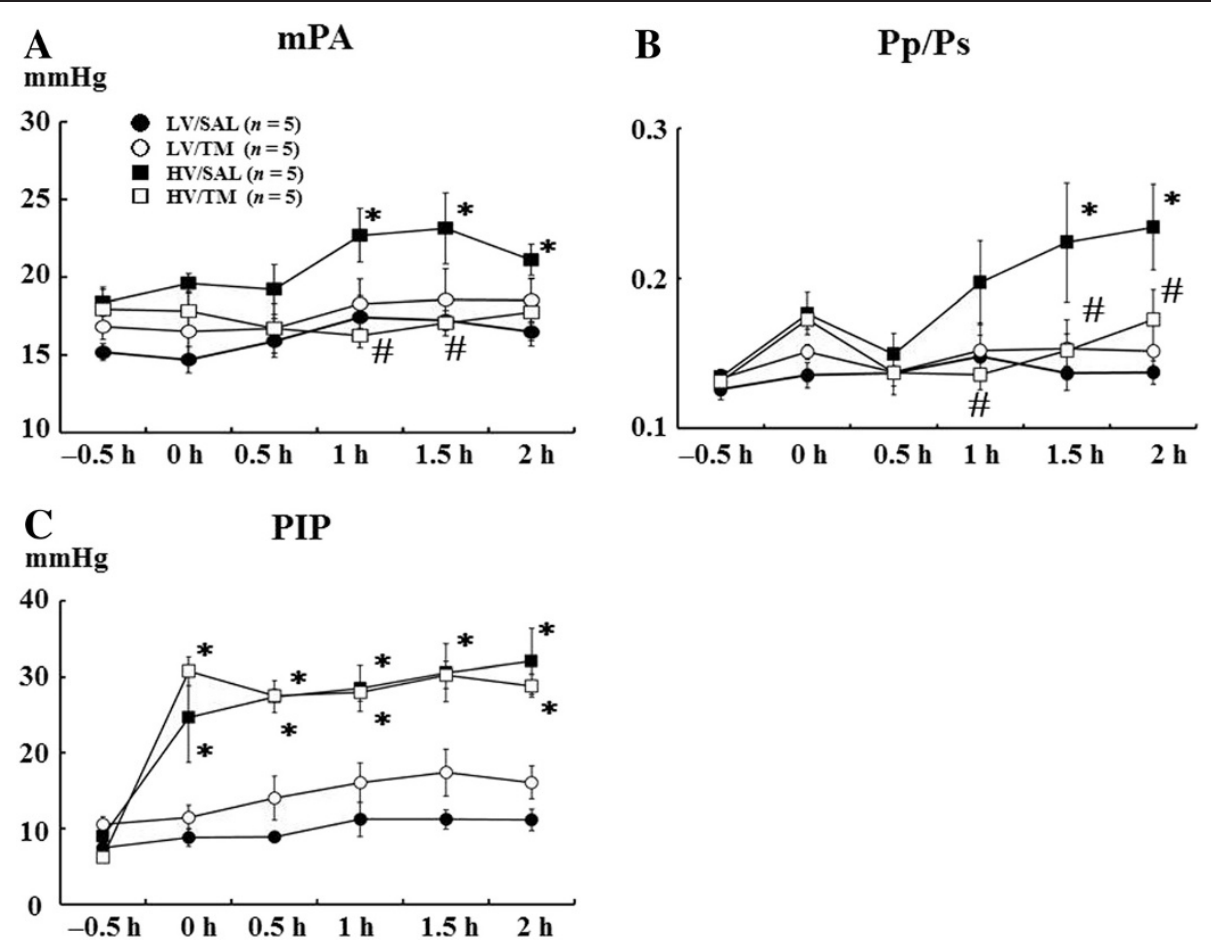

Figure 3 Mean pulmonary artery pressure, $\mathrm{Pp} / \mathrm{Ps}$, and peak inspiratory airway pressure. (A) Mean pulmonary artery pressure (mPAP), (B) the ratio of mean pulmonary artery pressure to mean artery pressure (Pp/Ps), (C) peak inspiratory airway pressure (PIP). (B) $-0.5 \mathrm{~h}$, baseline measurement before the start of experimental tidal volumes. See Figure 2 for other abbreviations. Bars indicate mean \pm SE. ${ }^{*} P<0.05$ versus the respective LV groups. $\# P<0.05$ versus the HV/SAL group. $n=$ number of rats.

were significantly higher in the HV/SAL group than in the LV/SAL group. These increases in IL- $1 \alpha$, IL-1 $\beta$, IL-6, and MIP-2 mRNA levels were significantly attenuated in the HV/TM group compared with the HV/SAL group (Figure 4). There was no difference in the level of TNFa mRNA between the HV/TM group and HV/SAL group.

\section{ROCK-1}

Because ROCK-1 protein level increased in the lung tissue in mice VILI model [9], we determined ROCK-1 mRNA and protein level in the lung tissue with and without TM treatment. There was no change in ROCK-1 mRNA expression among the groups (Figure 5A). ROCK-1 protein expression was significantly decreased in the HV/SAL group and HV/TM group compared with the LV/SAL group and LV/TM group, respectively (Figure 5B). No difference was found between the HV/SAL and HV/TM groups.

\section{HMGB-1}

Because TM has been shown to neutralize HMGB-1, a mediator of inflammation and increased permeability through activation of inducible nitric oxide synthase $[16,26]$, we investigated whether TM administration would reduce HMGB-1 mRNA and protein expressions in the lung in high tidal ventilation. Unexpectedly, HMGB-1 mRNA and protein expressions in the lung were significantly decreased in the HV/SAL group and HV/TM group compared with the LV/SAL group and LV/TM group, respectively. No difference was found between the HV/SAL and HV/TM groups (Figure 5C).

\section{Discussion}

The results of this study showed that high tidal volume ventilation with $100 \%$ oxygen induced lung injury, associated with the upregulation of proinflammatory cytokine mRNA in the injured lung. TM pretreatment attenuated the decrease in $\mathrm{PaO}_{2}$, lung permeability, and mPAP in VILI rats. Proinflammatory cytokine mRNA levels in the injured lung were decreased in VILI rats treated with TM.

Ventilation with high tidal volume and 100\% oxygen significantly upregulated protein permeability measured by EBD extravasation into the lung in rats. The lung dry/wet weight ratio was also nonsignificantly increased in the HV/SAL group compared with the LV/SAL group. These results suggest that EBD extravasation is more sensitive for detecting the increase in protein permeability in the lung than dry/wet weight ratios in the early phase of VILI. The EBD extravasation of LV with room air (LV group in preliminary experiment) and LV with $100 \%$ oxygen (LV/SAL group in main experiment) were similar. Thus, we could not detect apparent oxygen toxicity in the 

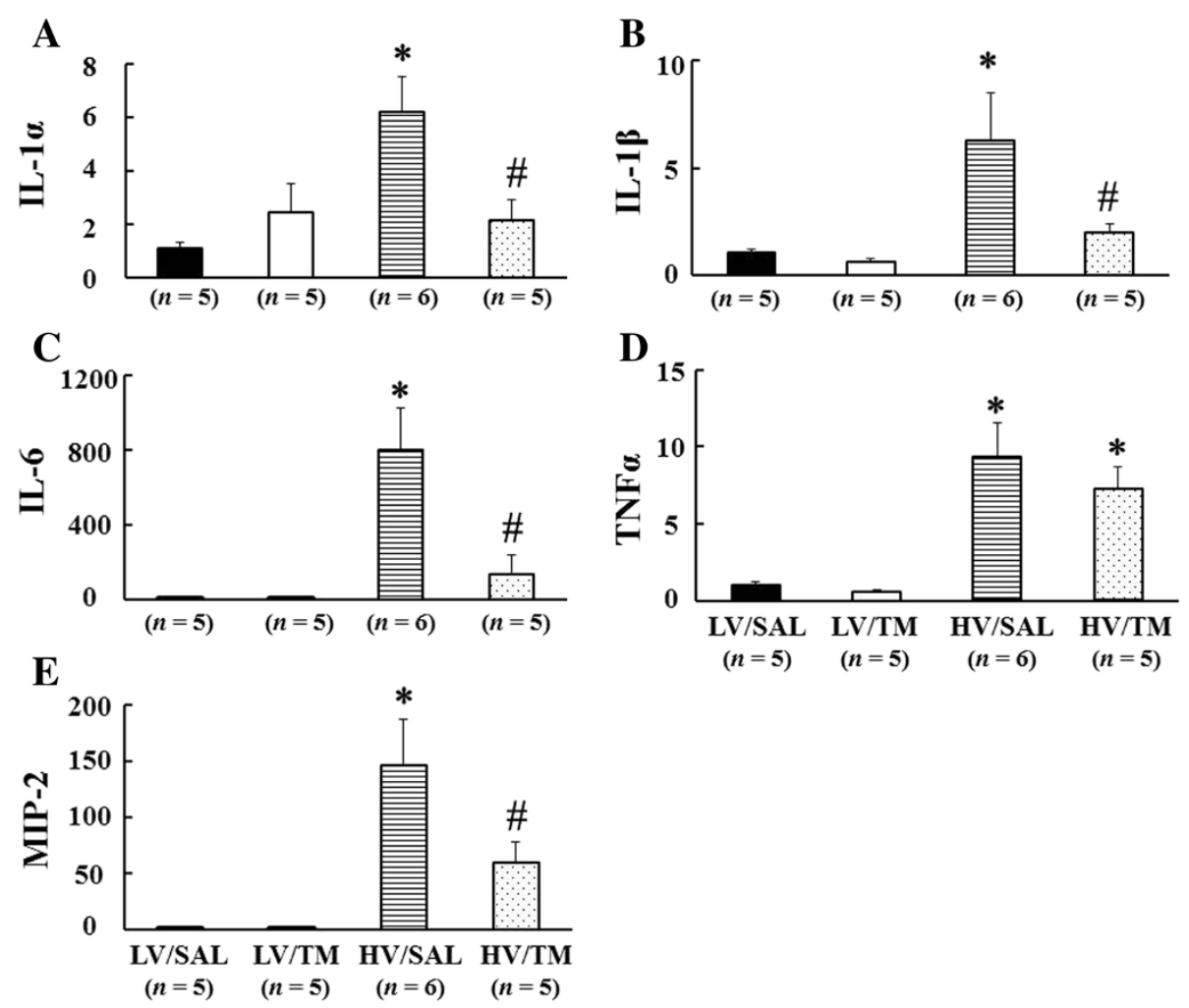

Figure 4 rhsTM attenuated the increase in cytokine and chemokine mRNA in VILI in rats. Cytokine [interleukin (IL)-1a (A), IL-1 13 (B), IL-6 (C), tumor necrosis factor a (TNFa) (D)] and chemokine (macrophage inflammatory protein (MIP)-2) (E) mRNA expressions in the lung tissue were significantly higher in the HV/SAL group than in the LV/SAL group. Note significant differences between the HV/TM group and HV/SAL group for IL-1a, IL-1 $\beta, I L-6$, and MIP-2. ${ }^{*} P<0.05$ versus the LV group. $\# P<0.05$ versus the HV/SAL group. $n=$ number of rats. See Figure 2 for abbreviations.

present experimental condition. These results indicate our lung injury model was induced by combined high level of oxygen and large tidal volume mechanical ventilation.

The results showed that TM administration prevented VILI, as evidenced by the reduction in protein leakage, attenuation of the decrease in arterial oxygenation in high tidal volume ventilation, and prevention of the increase in mPAP and Pp/Ps ratio. Although this protective effect of rhsTM was associated with a reduction of chemokine (MIP-2) and cytokine (IL- $1 \alpha$, IL-1 $\beta$, and IL-6) mRNA expression in the lungs with high volume ventilation, a causal relationship between VILI and these mediators remains to be determined [1]. An earlier study showed that IL-1 receptor antagonist protects against VILI in rabbits, suggesting that IL-1 is a candidate mediator of VILI [27].

\section{Cytokines and chemokines}

Expressions of proinflammatory cytokines (IL- $1 \alpha$, IL- $1 \beta$, IL-6, and TNF $\alpha$ ) in TM-untreated lung were significantly elevated following high volume ventilation, which confirms that a high volume ventilation is associated with a proinflammatory reaction. Since TNF $\alpha$ and IL- $1 \beta$ suppress TM mRNA in endothelial cells $[11,28]$, the increase in these cytokines in the present study shows a possible lack of
TM during high volume ventilation. A lack of TM is associated with activation of mitogen-activated kinase and an increase in $\mathrm{NF}_{\kappa} \mathrm{B}$ and ICAM expression [11], thereby potentiating the inflammatory reaction. If there is a lack of TM during high volume ventilation, TM administration could be used as a supplementation therapy. Because TM administration attenuates the increase in IL- 6 and IL-1 $\beta$ mRNA, the inflammatory response might be attenuated by TM supplementation. Additional experiment such as determination of TM concentration or TM staining in the lung tissue is necessary.

ROCK-1 protein expression was reduced in rats with high volume tidal ventilation, and TM had no effect on ROCK-1 expression. A previous study that found that expression of ROCK-1 in the lung was increased in VILI mice showed that APC-mediated vascular protection involves inhibition of ROCK-1 [9]. Upregulation of ROCK1 increases vascular permeability through endothelial gap formation [29]. However, this mechanism was not the case in the present study because ROCK-1 mRNA expression was unchanged. Species difference and model difference might explain the difference of ROCK-1 expression. Furthermore, TM administration might not increase APC in the present study, because rhsTM activates 


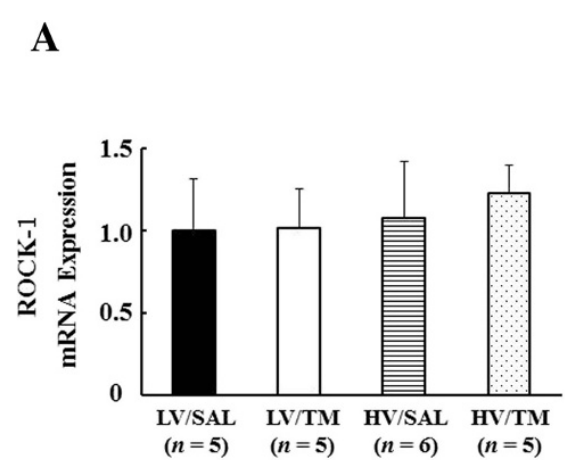

C

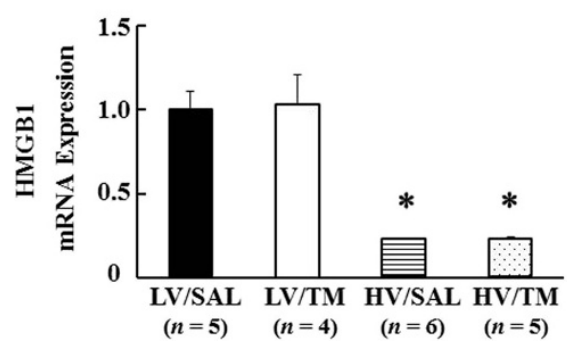

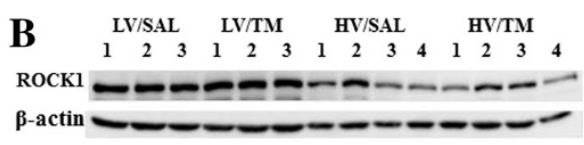

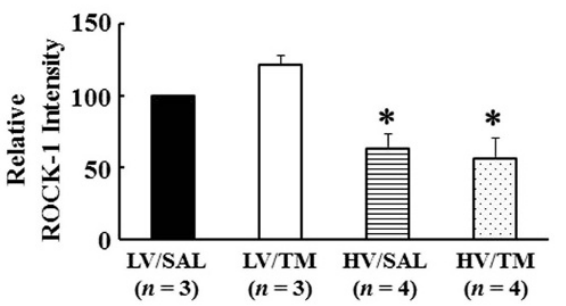

D
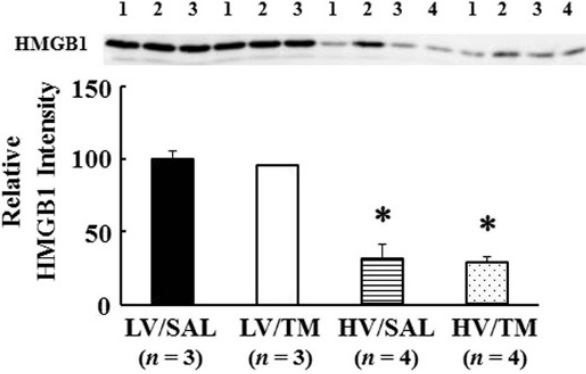

Figure 5 ROCK-1 and HMGB-1. (A) Rho-associated kinase (ROCK)-1 mRNA, (B) ROCK-1 protein expression, (C) high-mobility group box 1 (HMGB-1) mRNA, (D) HMGB-1 protein expression. For protein expression, the average intensity of LV/SAL was taken as 100\%. Each sample intensity as a percentage of the average was calculated (relative intensity). ${ }^{*} P<0.05$ versus the respective LV group. $n=$ number of rats. See Figure 2 for abbreviations.

protein $\mathrm{C}$ in human and monkey plasma but not in rat and rabbit [30].

Lung tissue MIP-2 mRNA levels were significantly reduced by TM treatment, which might delay the occurrence of early VILI. MIP-2, a rodent homologue of human IL-8 [31], is a potent monocyte attractant, initiating cellular migration and activation and inflammatory cell recruitment.

Since TM binds to HMGB-1 and promotes its degradation and inactivation in sepsis $[12,16,26]$, we measured HMGB-1 mRNA and protein expressions in the lung. Unexpectedly, HMGB-1 mRNA and protein expressions in the lungs were reduced in rats ventilated with high tidal volume. The decrease in HMGB-1 protein possibly might be due to less production since the HMGB-1 mRNA level was downregulated in rats with lung injury created by high level of oxygen with large tidal volume mechanical ventilation. Another possibility is that HMGB1 protein might be released into the systemic circulation from the lungs during the 2 -h ventilation. HMGB- 1 is normally present as a nuclear protein [32] and is passively released from damaged cells [26]. A recent study showed that the increase in serum HMGB-1 is associated with the concurrent decrease in tissue HMGB-1 protein expression of the liver in rat sinusoidal obstruction syndrome [33]. Since macrophages produce HMGB-1, the decrease in the number of macrophages might also explain the decrease in HMGB-1 protein levels in the lung tissue. An earlier study of bronchoalveolar lavage fluid and histology demonstrated that alveolar macrophages decreased in the VILI model [3]. We could not detect the effect of TM on HMGB-1 levels in the lung tissue. However, this result does not eliminate the possibility that TM binds plasma HMGB-1 that has been spread from the lung.

\section{Limitations and clinical implications}

The first limitation of this study is that it is observational and not mechanistic. Although observational, this is the first report showing that TM blocks the development of lung injury created by high level of oxygen with large tidal volume mechanical ventilation in an animal model. rhsTM (Asahi Kasei Pharma, Tokyo, Japan) has been approved in Japan since 2008 for the treatment of DIC with hematologic malignancy or infection. Following a phase IIb global trial [32], a subsequent phase III global trial of rhsTM for patients with sepsis-associated coagulopathy is now underway. An observational clinical study showed improvement in respiratory dysfunction in patients with severe sepsis, in which the therapies included mechanical ventilation [34]. Thus, the numbers of septic patients under both mechanical ventilation and rhsTM administration have been increasing [35]. If rhsTM blocks the development of VILI, this beneficial effect would not be limited to just those patients with 
coagulopathy. Second, we could not differentiate between the effect of high tidal volume and $100 \%$ oxygen. The model of VILI should be clearly different from oxygen toxicity, although the latter exacerbates the pathology of the former. Since our preliminary study showed difficulties to induce VILI with high tidal volume ventilation $(30-40 \mathrm{ml} / \mathrm{kg})$ in room air and VILI was induced with $100 \%$ oxygen inhalation in other studies [2,21-23], our rats were ventilated with high tidal volume with $100 \%$ oxygen inhalation. Two hit lung injury, i.e., high tidal volume and $100 \%$ oxygen inhalation, induced lung injury in the present study. In patients under mechanical ventilation, high oxygen inhalation is relatively common. Third, in the present study, healthy lungs were ventilated with a tidal volume of $35 \mathrm{ml} / \mathrm{kg}$ with resultant high peak inspiratory pressure. Although a tidal volume of $35 \mathrm{ml} / \mathrm{kg}$ is unrealistic in the clinical setting, a moderate tidal volume of $10-12 \mathrm{ml} / \mathrm{kg}$ in patients with ARDS might cause a region of overdistension equivalent to that of $40 \mathrm{ml} / \mathrm{kg}$ ventilation because of nonhomogeneity due to a mixture of ventilated and nonventilated regions in the lung [1]. Fourth, the duration of mechanical ventilation was short, as in other similar studies $[1,3,4,9]$, which is different from the clinical setting. Thus, we can only say that even short-term high tidal ventilation can induce VILI. Fifth, the number of animals might be small to judge the exact effect of TM on VILI. From the ethical standpoint of animal experiment, we saved the number of animals to be sacrificed.

\section{Conclusions}

In summary, the results of this study show that rhsTM administration protects against the development of lung injury in an experimental setting, which has concomitant decrease in cytokine mRNA expression in the lung tissue from rats with the lung injury created by high level of oxygen with large tidal volume mechanical ventilation.

\section{Competing interests}

The authors declare that they have no competing interests.

\section{Authors' contributions}

$\mathrm{YI}$ and EZ contributed equally to this work, collecting and analyzing the data, and drafting the manuscript. JM and $Y Y$ set up the mechanical ventilator and pressure measurement system. AY, YM, and HS interpreted the data. HI interpreted the clinical role of rhsTM. KS participated in the design of the study for determining the effects of rhsTM. KM conceived the study, participated in its design and coordination, and helped to draft the manuscript. All authors read and approved the final manuscript.

\section{Acknowledgements}

The authors thank Drs. R. Azuma, Y. Hashimoto, H. Ohashi, A. Inami, and A Ohmori, Ms. F. Ohmoto, T. Chen, R. Nanba, and Mr. S. Harada, students of Mie University School of Medicine, for their help. We are also grateful to Ms. A. Okada and N. Hiramatsu for the technical and secretarial assistance. This work was supported in part by Grants-In-Aid for Scientific Research from the Japan Society for the Promotion of Science.

\section{Author details}

'Department of Anesthesiology and Critical Care Medicine, School of Medicine, Mie University, 2-174 Edobashi, Tsu, Mie 5148507, Japan. ${ }^{2}$ Department of Pediatrics, School of Medicine, Mie University, Tsu, Mie, Japan. ${ }^{3}$ Department of Emergency Critical Care Center, Mie University School of Medicine, 2-174 Edobashi, Tsu, Mie 514-8507, Japan. ${ }^{4}$ Department of Medical Engineering, Suzuka University of Medical Science, 1001-1 Kishiokacho, Suzuka, Mie 510-0226, Japan. ${ }^{5}$ Department of Pharmacological Science, Suzuka University of Medical Science, 1001-1 Kishiokacho, Suzuka, Mie 510-0226, Japan.

Received: 10 June 2014 Accepted: 17 September 2014

Published online: 01 October 2014

\section{References}

1. Tremblay LN, Slutsky AS: Ventilator-induced lung injury: from the bench to the bedside. Intensive Care Med 2006, 32:24-33.

2. Chiumello D, Pristine G, Slutsky AS: Mechanical ventilation affects local and systemic cytokines in an animal model of acute respiratory distress syndrome. Am J Respir Crit Care Med 1999, 160:109-116.

3. Imanaka H, Shimaoka M, Matsuura N, Nishimura M, Ohta N, Kiyono H: Ventilator-induced lung injury is associated with neutrophil infiltration, macrophage activation, and TGF-beta 1 mRNA upregulation in rat lungs. Anesth Analg 2001, 92:428-436.

4. Tremblay L, Valenza F, Ribeiro SP, Li J, Slutsky AS: Injurious ventilatory strategies increase cytokines and c-fos m-RNA expression in an isolated rat lung model. J Clin Invest 1997, 99:944-952.

5. Ranieri VM, Suter PM, Tortorella C, De Tullio R, Dayer JM, Brienza A, Bruno F, Slutsky AS: Effect of mechanical ventilation on inflammatory mediators in patients with acute respiratory distress syndrome: a randomized controlled trial. JAMA 1999, 282:54-61.

6. The Acute Respiratory Distress Syndrome Network: Ventilation with lower tidal volumes as compared with traditional tidal volumes for acute lung injury and the acute respiratory distress syndrome. N Engl J Med 2000, 342:1301-1308.

7. Futier E, Constantin JM, Paugam-Burtz C, Pascal J, Eurin M, Neuschwander A, Marret E, Beaussier M, Gutton C, Lefrant JY, Allaouchiche B, Verzilli D, Leone M, De Jong A, Bazin JE, Pereira B, Jaber S, IMPROVE Study Group: A trial of intraoperative low-tidal-volume ventilation in abdominal surgery. $N$ Engl J Med 2013, 369:428-437

8. Haitsma JJ, Schultz MJ, Hofstra JJ, Kuiper JW, Juco J, Vaschetto R, Levi M, Zhang $H$, Slutsky AS: Ventilator-induced coagulopathy in experimental Streptococcus pneumoniae pneumonia. Eur Respir J 2008, 32:1599-1606.

9. Finigan JH, Boueiz A, Wilkinson E, Damico R, Skirball J, Pae HH, Damarla M, Hasan E, Pearse DB, Reddy SP, Grigoryev DN, Cheadle C, Esmon CT, Garcia JG, Hassoun PM: Activated protein C protects against ventilator-induced pulmonary capillary leak. Am J Physiol Lung Cell Mol Physiol 2009, 296:L1002-L1011.

10. Weiler H, Isermann BH: Thrombomodulin. J Thromb Haemost 2003, 1:1515-1524.

11. Van de Wouwer M, Conway EM: Novel functions of thrombomodulin in inflammation. Crit Care Med 2004, 32(5 Suppl):S254-\$261.

12. Ito T, Maruyama I: Thrombomodulin: protectorate God of the vasculature in thrombosis and inflammation. J Thromb Haemost 2011, 9(Suppl 1):168-173.

13. Sitrin RG, Pan PM, Srikanth S, Todd RF 3rd: Fibrinogen activates NF-kappa B transcription factors in mononuclear phagocytes. J Immunol 1998, 161:1462-1470.

14. Okamoto T, Tanigami H, Suzuki K, Shimaoka M: Thrombomodulin: a bifunctional modulator of inflammation and coagulation in sepsis. Crit Care Res Pract 2012, 2012:614545.

15. Johnson K, Choi Y, DeGroot E, Samuels I, Creasey A, Aarden L: Potential mechanisms for a proinflammatory vascular cytokine response to coagulation activation. J Immunol 1998, 160:5130-5135.

16. Riedemann NC, Guo RF, Ward PA: Novel strategies for the treatment of sepsis. Nat Med 2003, 9:517-524.

17. Kumagai M, Horiguchi T, Nishikawa T, Masaki Y, Tobe Y: Intravenous dexmedetomidine decreases lung permeability induced by intracranial hypertension in rats. Anesth Analg 2008, 107:643-647.

18. Teke Z, Sacar M, Yenisey C, Atalay AO, Bicakci T, Erdem E: Activated protein C attenuates intestinal reperfusion-induced acute lung injury: an experimental study in a rat model. Am J Surg 2008, 195:861-873. 
19. Yamada Y, Maruyama J, Zhang E, Okada A, Yokochi A, Sawada H, Mitani Y, Hayashi T, Suzuki K, Maruyama K: Effect of thrombomodulin on the development of monocrotaline-induced pulmonary hypertension. $J$ Anesth 2014, 28:26-33.

20. Maruyama J, Maruyama K, Mitani Y, Kitabatake M, Yamauchi T, Miyasaka K: Continuous low-dose NO inhalation does not prevent monocrotalineinduced pulmonary hypertension in rats. Am J Physiol 1997, 272:H517-H524.

21. DiRocco JD, Pavone LA, Carney DE, Lutz CJ, Gatto LA, Landas SK, Nieman GF: Dynamic alveolar mechanics in four models of lung injury. Intensive Care Med 2006, 32:140-148.

22. Li LF, Liao SK, Ko YS, Lee CH, Quinn DA: Hyperoxia increases ventilator-induced lung injury via mitogen-activated protein kinases: a prospective, controlled animal experiment. Crit Care 2007, 11:R25.

23. Wilson MR, Choudhury S, Goddard ME, O'Dea KP, Nicholson AG, Takata M: High tidal volume upregulates intrapulmonary cytokines in an in vivo mouse model of ventilator-induced lung injury. J Appl Physiol 2003, 95:1385-1393.

24. Zapol WM, Snider MT: Pulmonary hypertension in severe acute respiratory failure. N Engl J Med 1977, 296:476-480.

25. Maruyama K, Maruyama J, Utsunomiya H, Furuhashi K, Kurobuchi M, Katayama Y, Yada I, Muneyuki M: Effect of nicardipine on pulmonary hypertension after repair of congenital heart defects in early postoperative period. J Anesth 1993, 7:95-101.

26. Andersson $\mathrm{U}$, Tracey KJ: HMGB1 is a therapeutic target for sterile inflammation and infection. Annu Rev Immunol 2011, 29:139-162.

27. Narimanbekov IO, Rozycki HJ: Effect of IL-1 blockade on inflammatory manifestations of acute ventilator-induced lung injury in a rabbit model. Exp Lung Res 1995, 21:239-254.

28. Conway EM, Rosenberg RD: Tumor necrosis factor suppresses transcription of the thrombomodulin gene in endothelial cells. Mol Cell Biol 1988, 8:5588-5592.

29. Wojciak-Stothard B, Ridley AJ: Rho GTPases and the regulation of endothelial permeability. Vascul Pharmacol 2002, 39:187-199.

30. Mohri M, Gonda Y, Oka M, Aoki Y, Gomi K, Kiyota T, Sugihara T, Yamamoto S, Ishida T, Maruyama I: The antithrombotic effects of recombinant human soluble thrombomodulin (rhsTM) on tissue factor-induced disseminated intravascular coagulation in crab-eating monkeys (Macaca fascicularis). Blood Coagul Fibrinolysis 1997, 8:274-283.

31. Mourgeon E, Isowa N, Keshavjee S, Zhang X, Slutsky AS, Liu M: Mechanical stretch stimulates macrophage inflammatory protein-2 secretion from fetal rat lung cells. Am J Physiol Lung Cell Mol Physiol 2000, 279:L699-L706.

32. Vincent IL, Ramesh MK, Ernest D, LaRosa SP, Pachl J, Aikawa N, Hoste E, Levy H, Hirman J, Levi M, Daga M, Kutsogiannis DJ, Crowther M, Bernard GR, Devriendt J, Puigserver JV, Blanzaco DU, Esmon CT, Parrillo JE, Guzzi L, Henderson SJ, Pothirat C, Mehta P, Fareed J, Talwar D, Tsuruta K, Gorelick KJ, Osawa Y, Kaul l: A randomized, double-blind, placebo-controlled, phase $2 \mathrm{~b}$ study to evaluate the safety and efficacy of recombinant human soluble thrombomodulin, ART-123, in patients with sepsis and suspected disseminated intravascular coagulation. Crit Care Med 2013, 41:2069-2079.

33. Nakamura K, Hatano E, Miyagawa-Hayashino A, Okuno M, Koyama Y, Narita M, Seo S, Taura K, Uemoto S: Soluble thrombomodulin attenuates sinusoidal obstruction syndrome in rat through suppression of high mobility group box 1. Liver Int 2013, doi:10.1111/iv.12420. [Epub ahead of print].

34. Ogawa Y, Yamakawa K, Ogura H, Kiguchi T, Mohri T, Nakamori Y, Kuwagata Y, Shimazu T, Hamasaki T, Fujimi S: Recombinant human soluble thrombomodulin improves mortality and respiratory dysfunction in patients with severe sepsis. J Trauma Acute Care Surg 2012, 72:1150-1157.

35. Wada H, Matsumoto T, Yamashita Y: Diagnosis and treatment of disseminated intravascular coagulation (DIC) according to four DIC guidelines. Journal of Intensive Care 2014, 2:15.

doi:10.1186/s40560-014-0057-0

Cite this article as: Iwashita et al.: Thrombomodulin protects against lung damage created by high level of oxygen with large tidal volume mechanical ventilation in rats. Journal of Intensive Care 2014 2:57.

\section{Submit your next manuscript to BioMed Central and take full advantage of:}

- Convenient online submission

- Thorough peer review

- No space constraints or color figure charges

- Immediate publication on acceptance

- Inclusion in PubMed, CAS, Scopus and Google Scholar

- Research which is freely available for redistribution

Submit your manuscript at www.biomedcentral.com/submit
C Biomed Central 